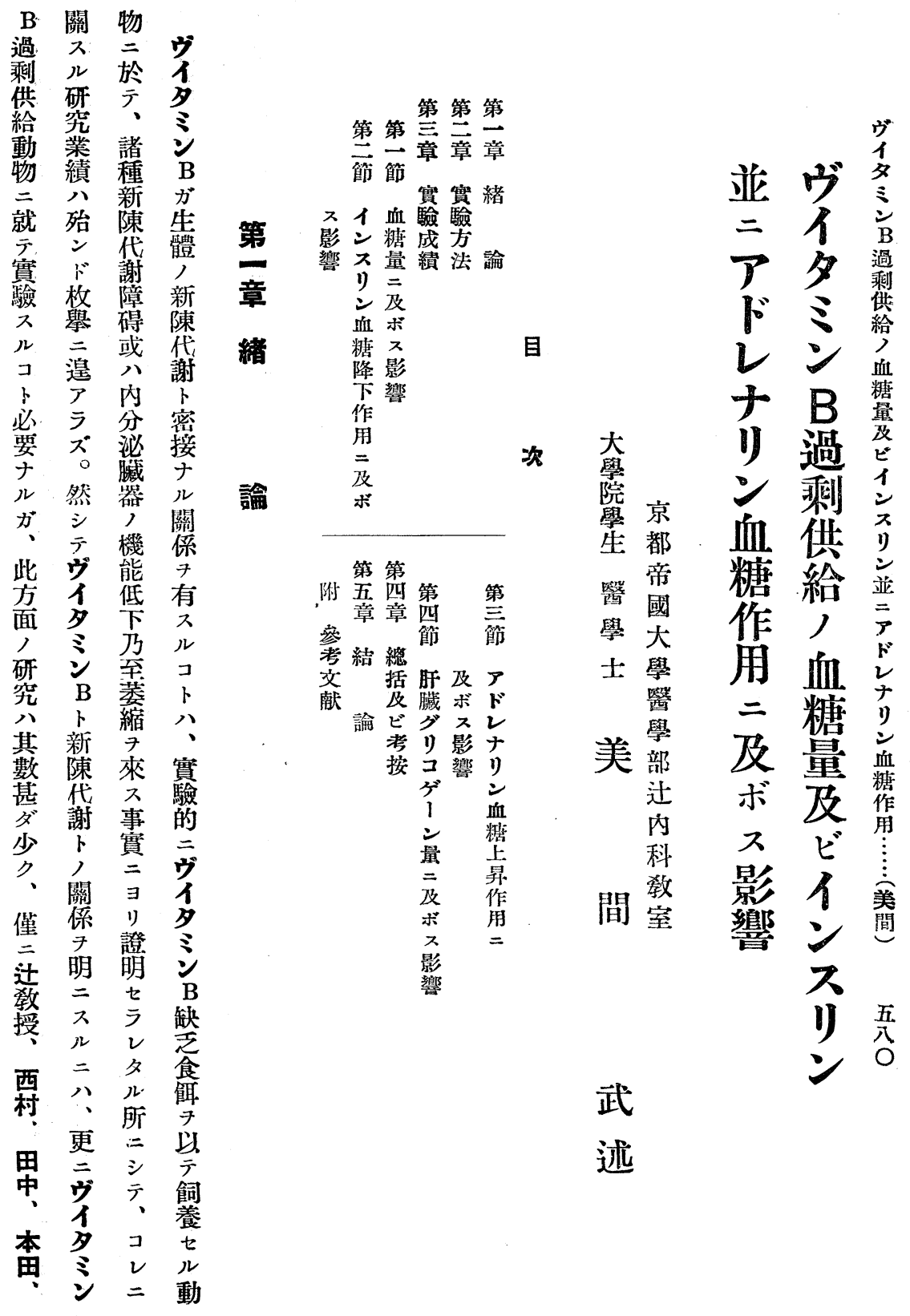




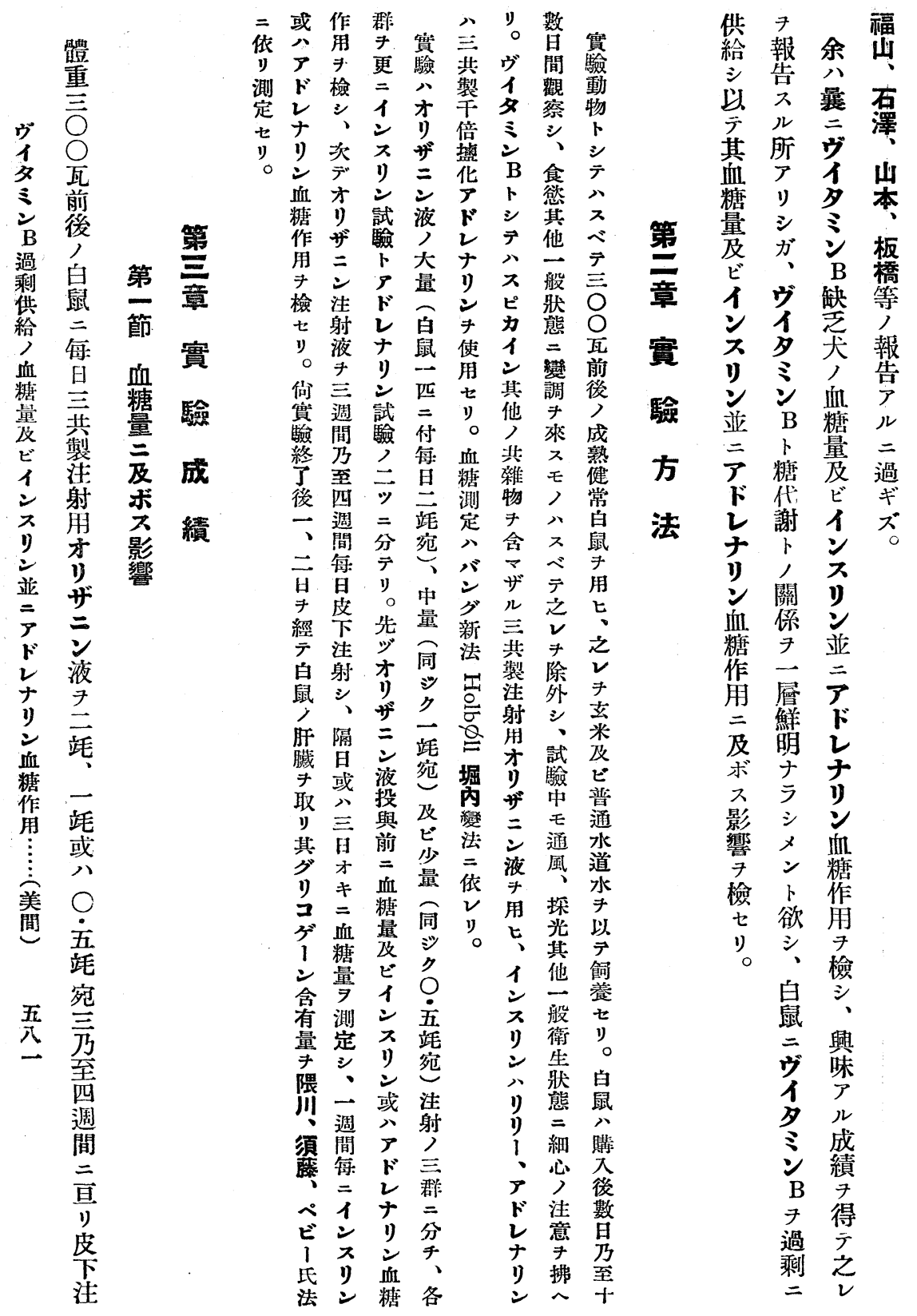




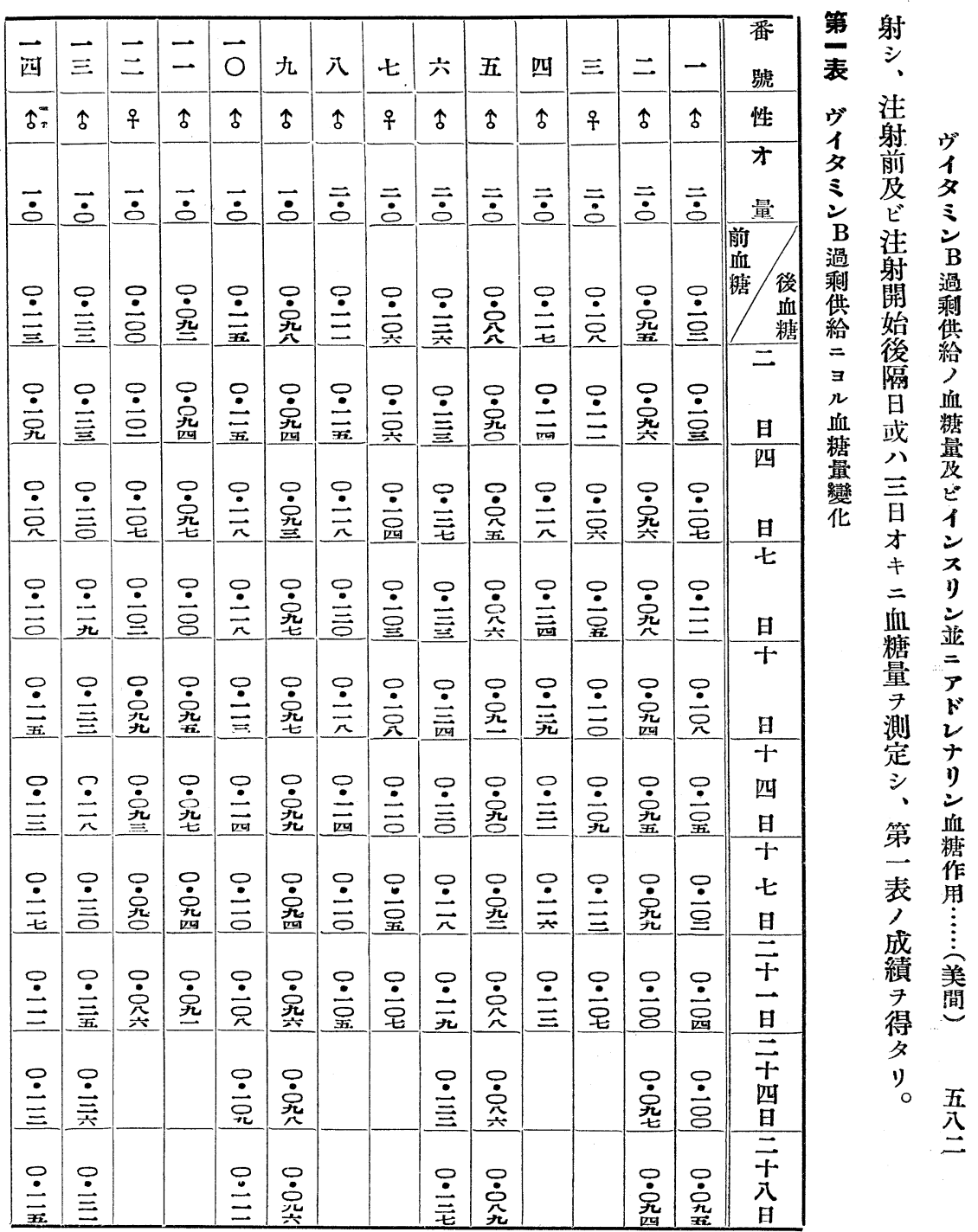




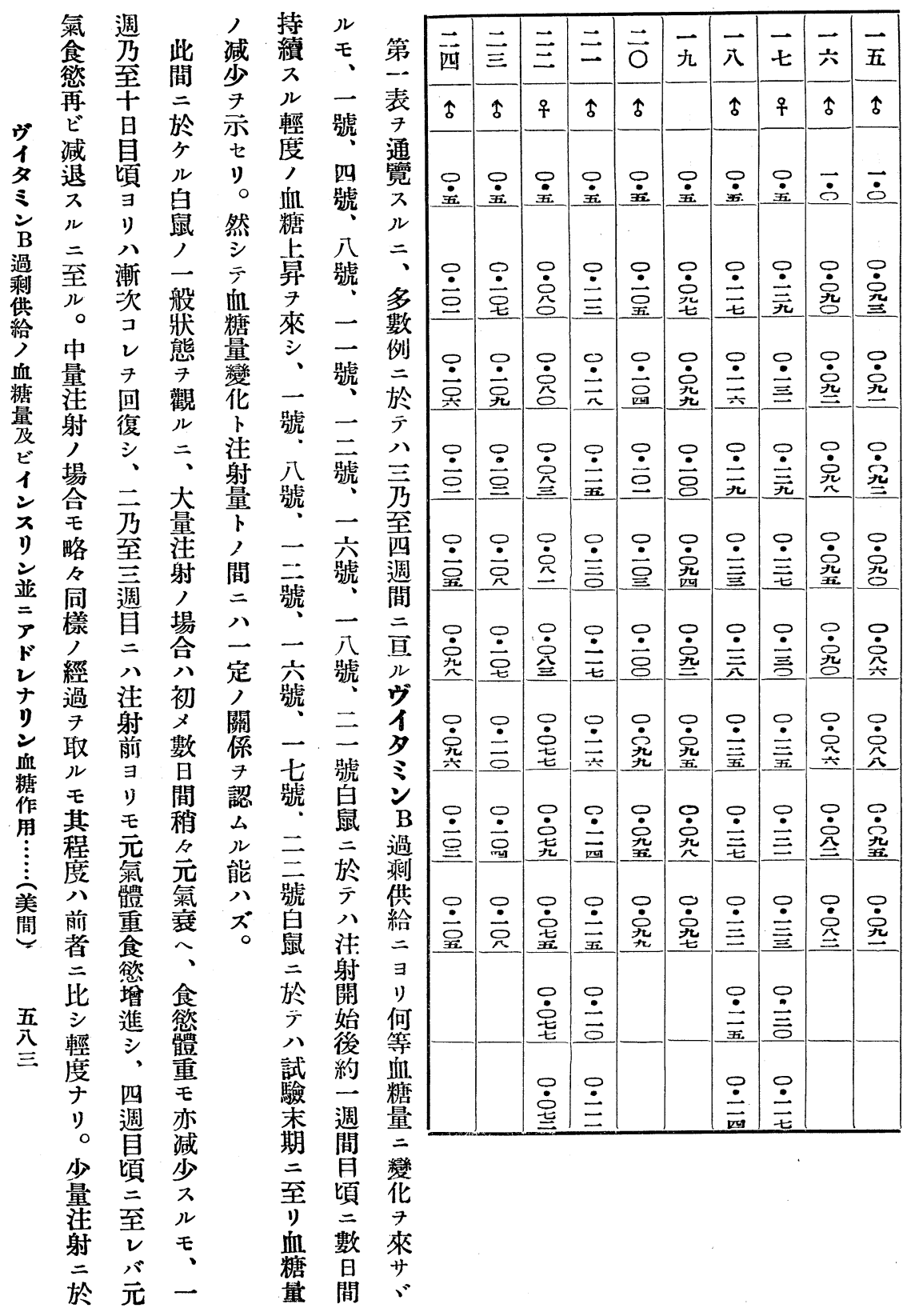




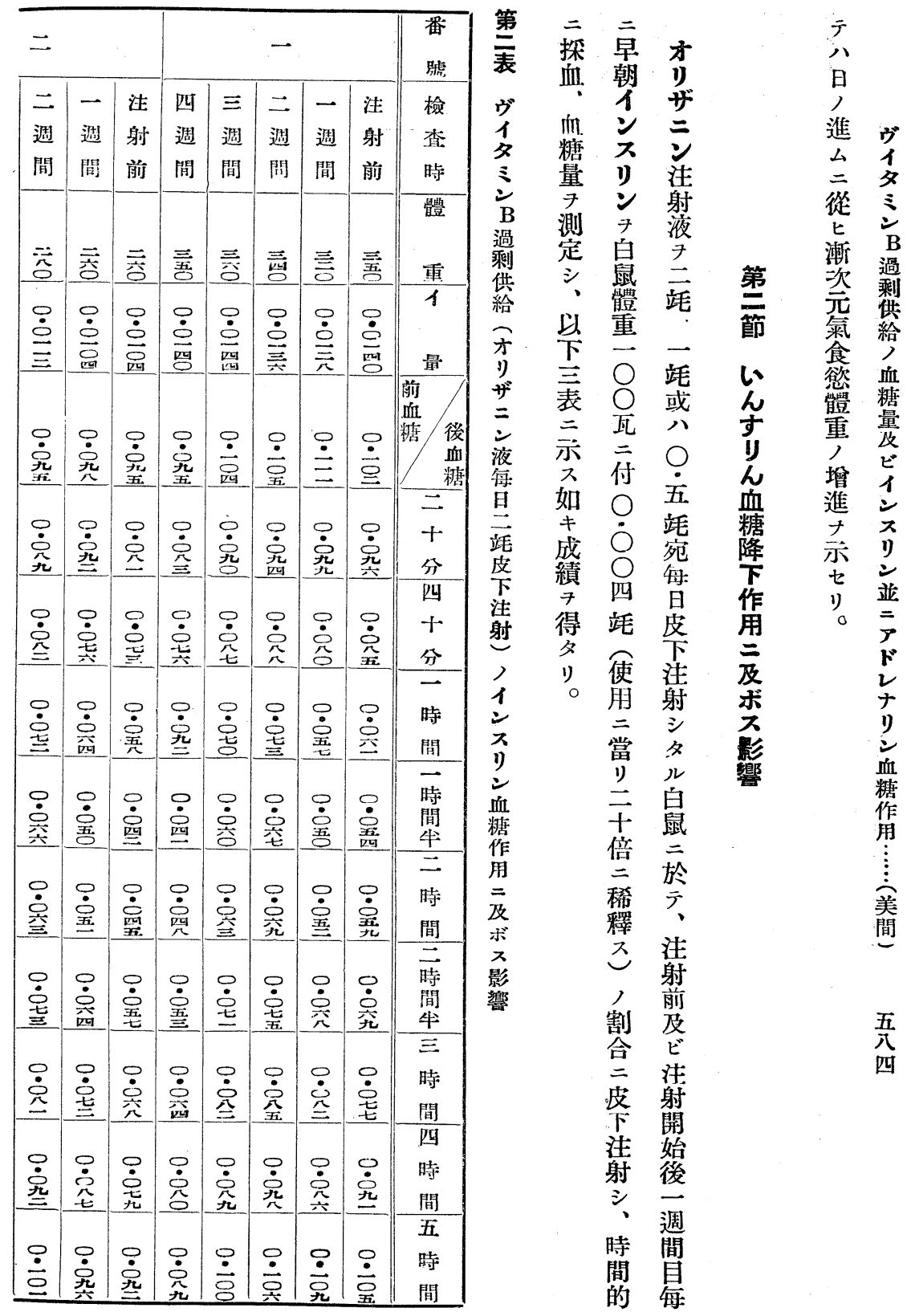




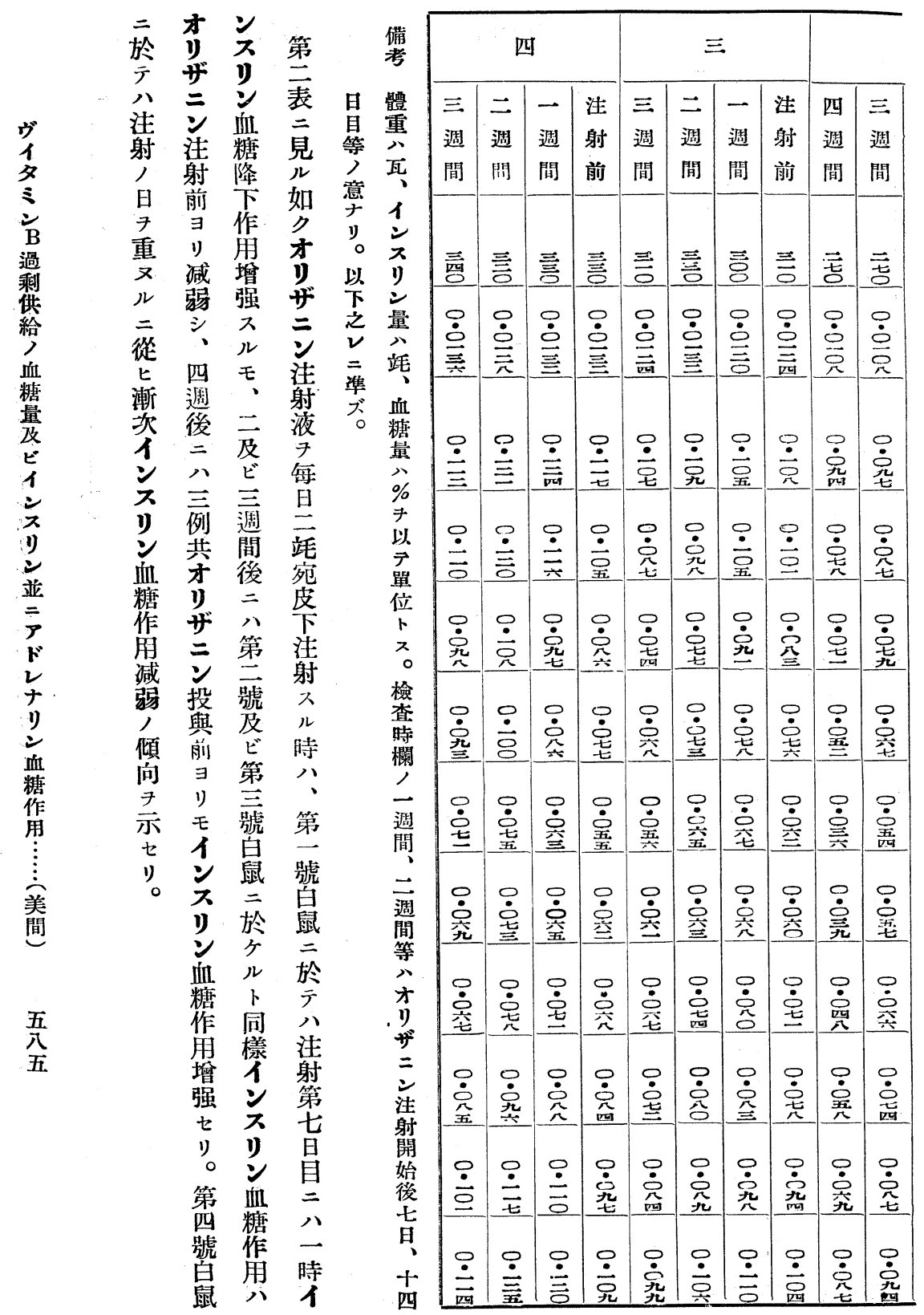



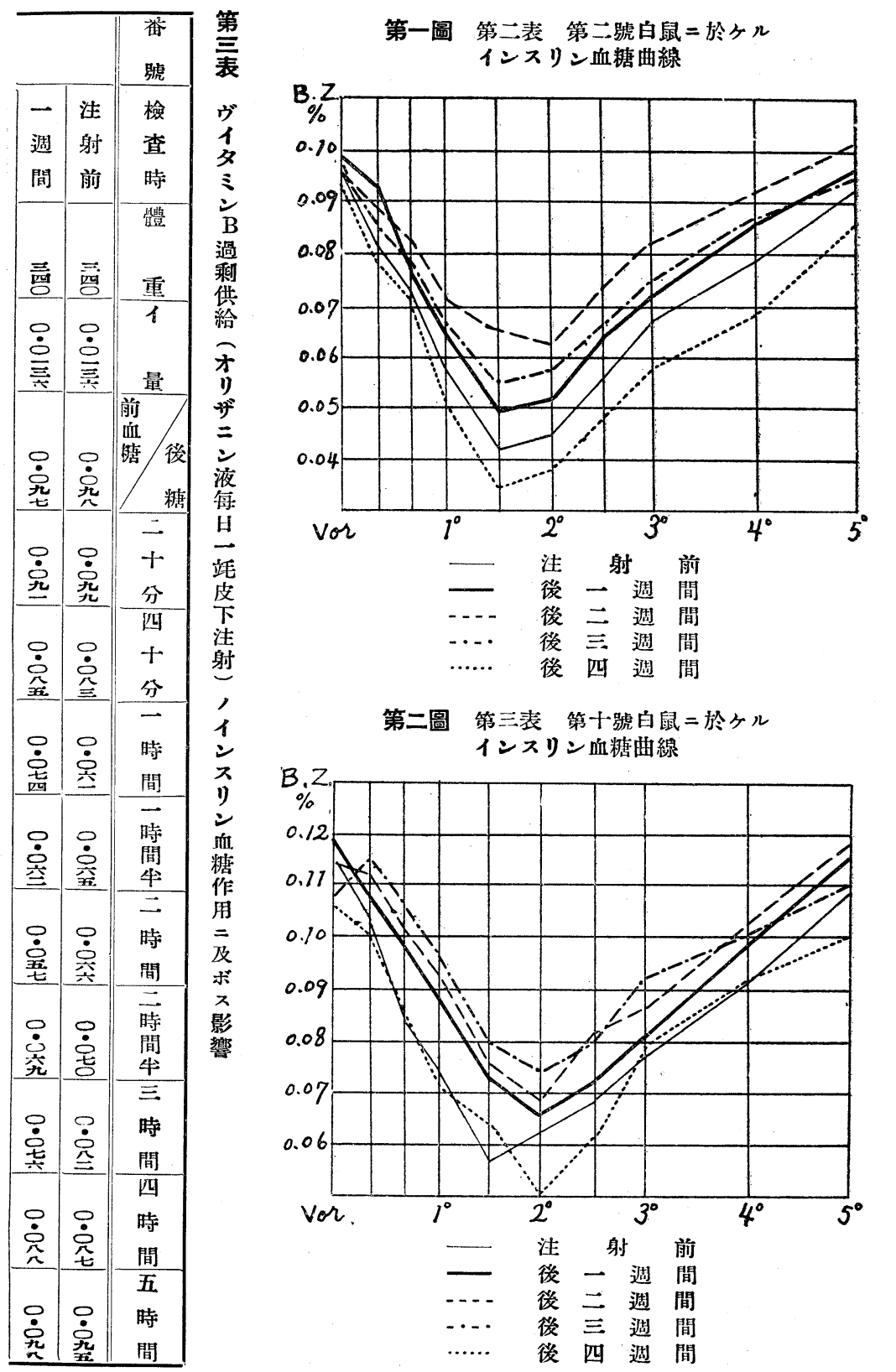

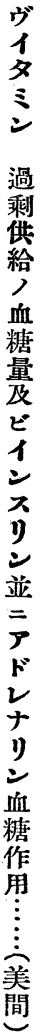

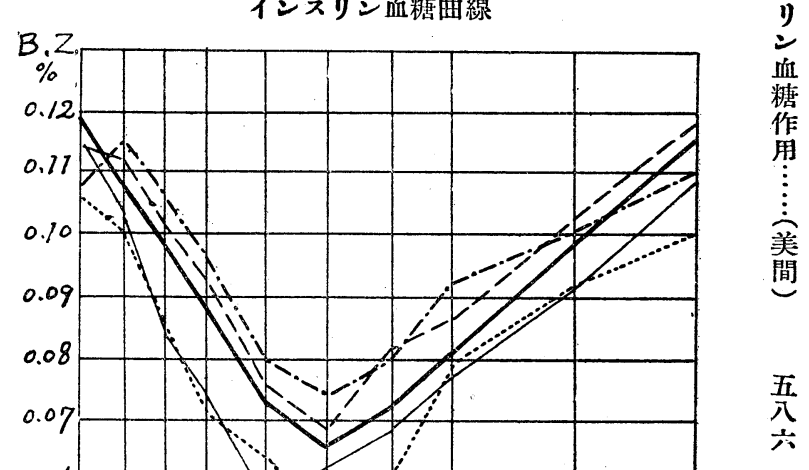




\begin{tabular}{|c|c|c|c|c|c|c|c|c|c|c|c|c|c|c|c|c|}
\hline \multirow{4}{*}{ 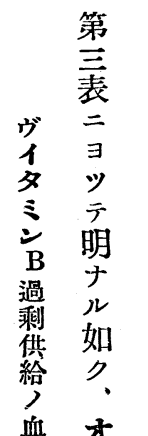 } & \multicolumn{4}{|c|}{$\equiv$} & \multicolumn{4}{|c|}{-} & \multicolumn{5}{|c|}{0} & \\
\hline & $\begin{array}{l}\text { 遇 } \\
\text { 間 }\end{array}$ & 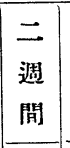 & $\begin{array}{l}\text { 週 } \\
\text { 間 }\end{array}$ & \begin{tabular}{|l} 
注 \\
射 \\
前
\end{tabular} & $\begin{array}{l}\text { 適 } \\
\text { 閔 }\end{array}$ & 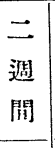 & 音成阔 & \begin{tabular}{|l} 
注 \\
射 \\
前 \\
\end{tabular} & $\begin{array}{l}\text { 四 } \\
\text { 僴 }\end{array}$ & $\begin{array}{l}\text { 迵 } \\
\text { 問 }\end{array}$ & $\begin{array}{l}\text { 迵 } \\
\text { 閏 }\end{array}$ & $\begin{array}{l}\text { 迺 } \\
\text { 間 }\end{array}$ & $\begin{array}{l}\text { 洼 } \\
\text { 的 } \\
\text { 前 }\end{array}$ & 罣 & 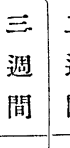 & $\begin{array}{l}\text { 週 } \\
\text { 間 }\end{array}$ \\
\hline & $\overrightarrow{\bar{E}}$ & 吾 & $\overrightarrow{\overline{\mathbf{z}}}$ & 言 & 言 & 言 & क्षे & $\overrightarrow{\overrightarrow{\underline{a}}}$ & 言 & 言 & $\overline{\bar{g}}$ & 吾 & 홍 & 룔 & 咅 & 害 \\
\hline & $\begin{array}{l}\dot{0} \\
\dot{0}\end{array}$ & $\begin{array}{l}0 \\
\dot{0} \\
\dot{\alpha}\end{array}$ & $\begin{array}{l}\dot{0} \\
\dot{0}\end{array}$ & 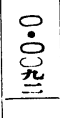 & $\begin{array}{l}0 \\
\dot{0} \\
\overline{v u}\end{array}$ & 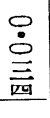 & $\dot{\dot{\theta}}$ & $\dot{\dot{\theta}}$ & 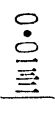 & 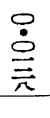 & $\begin{array}{l}\stackrel{\dot{\theta}}{\bar{z}} \\
\end{array}$ & 总 & $\dot{\dot{\theta}}$ & 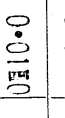 & 离 & 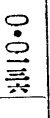 \\
\hline & $\begin{array}{l}\dot{\vdots} \\
\dot{\lambda}\end{array}$ & $\begin{array}{l}0 \\
\dot{i}\end{array}$ & $\stackrel{\dot{\bar{\sigma}}}{ }$ & $\dot{\dot{\theta}}$ & $\stackrel{\ominus}{\dot{c}}$ & $\stackrel{8}{\dot{i}}$ & $\dot{\dot{\bar{\theta}}}$ & $\stackrel{\dot{\imath}}{\mathrm{c}}$ & $\stackrel{\stackrel{\rho}{\dot{0}}}{ }$ & $\dot{\dot{\sigma}}$ & $\stackrel{\stackrel{P}{\doteq}}{ }$ & $\stackrel{P}{\doteq}$ & $\stackrel{\rho}{\dot{\Xi}}$ & 完 & $\stackrel{\dot{i}}{\dot{\mathrm{c}}}$ & 竞 \\
\hline & $\stackrel{\dot{c}}{\dot{c}}$ & 家 & $\stackrel{8}{\dot{i}}$ & $\dot{\dot{c}}$ & $\dot{\dot{\varepsilon}}$ & $\dot{a}$ & $\dot{i}$ & $\dot{\dot{t}}$ & $\stackrel{\stackrel{亠}{0}}{ }$ & 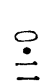 & $\stackrel{\stackrel{\rho}{\doteq}}{ }$ & $\stackrel{9}{9}$ & $\stackrel{\circ}{\dot{0}}$ & 竞 & $\stackrel{\dot{\tau}}{\dot{\tau}}$ & $\dot{\dot{\partial}}$ \\
\hline & & & $\because$ & $\stackrel{9}{9}$ & 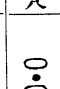 & 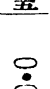 & $\therefore$ & & : & 9 & & 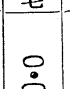 & & $\dot{\sigma}$ & & $\dot{0}$ \\
\hline 㖕 & & 量 & 恣 & 筀 & 疍 & s: & 导 & & & & & & 祭 & & & \\
\hline & 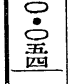 & 总 & 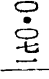 & 总 & 喔 & $\begin{array}{l}\text { 总荎 } \\
\end{array}$ & 总 & 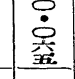 & 兽 & 宛 & 尊 & 蓄 & 总 & 完 & 颜 & 总 \\
\hline & 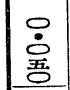 & 咅 & 紊 & 放 & $\dot{\rho}$ & 金 & $\begin{array}{l}\dot{\dot{\theta}} \\
\text { 要 }\end{array}$ & $\begin{array}{l}\dot{\dot{\theta}} \\
\dot{\underline{\underline{\theta}}}\end{array}$ & 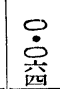 & $\begin{array}{l}\dot{\hat{j}} \\
\end{array}$ & 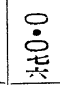 & 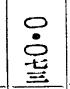 & 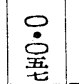 & 竞 & 啹 & 童 \\
\hline 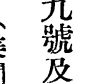 & $\dot{\dot{x}}$ & ? & $\stackrel{8}{0}$ & $\stackrel{8}{8}$ & $?$ & $\stackrel{8}{\dot{0}}$ & : & & 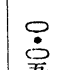 & & & $\stackrel{8}{\dot{0}}$ & $\stackrel{8}{\dot{s}}$ & : & $\stackrel{0}{\dot{0}}$ & $\dot{x}$ \\
\hline 第 & 9 & & & & & & & & & & & & & & & \\
\hline & 曾 & $\dot{\underline{\underline{\Sigma}}}$ & 家 & 童 & 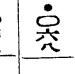 & 突 & 蕫 & 聜 & $\dot{S}$ & $\dot{\hat{a}}$ & $\dot{\underline{\underline{\underline{c}}}}$ & 家 & 突 & 寡 & 豈 & 䆓 \\
\hline & 总 & & $\begin{array}{l}\text { 完 } \\
\text { 管 }\end{array}$ & 晏 & $=\begin{array}{l}P \\
\dot{\hat{\theta}}\end{array}$ & 总 & 童 & 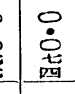 & 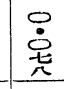 & 并 & 晏 & $\begin{array}{l}\dot{0} \\
\dot{\underline{\lambda}}\end{array}$ & 咅 & $\begin{array}{l}0 \\
\dot{\vdots} \\
\end{array}$ & 总 & 离离 \\
\hline & 总 & 光 & $\stackrel{\dot{\dot{\theta}}}{\underline{\underline{\theta}}}$ & 商童 & 完 & 总 & 克 & $\dot{0}$ & 咲 & $\dot{\dot{\theta}}$ & $\dot{\overrightarrow{\dot{\Xi}}}$ & $\begin{array}{l}\text { 莞 } \\
\end{array}$ & 尊 & 层 & 总 & \\
\hline & $\underline{\underline{\underline{\Omega}}}$ & ? & $\dot{\bar{t}}$ & $\dot{\bar{\theta}}$ & 密 & 完 & 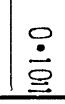 & 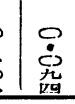 & $\dot{\dot{亠}}$ & $\stackrel{\stackrel{\Xi}{\Xi}}{ }$ & $\dot{\bar{\lambda}}$ & & $\mid \begin{array}{l}\dot{\bar{c}} \\
\end{array}$ & & $\mid$ & \\
\hline
\end{tabular}




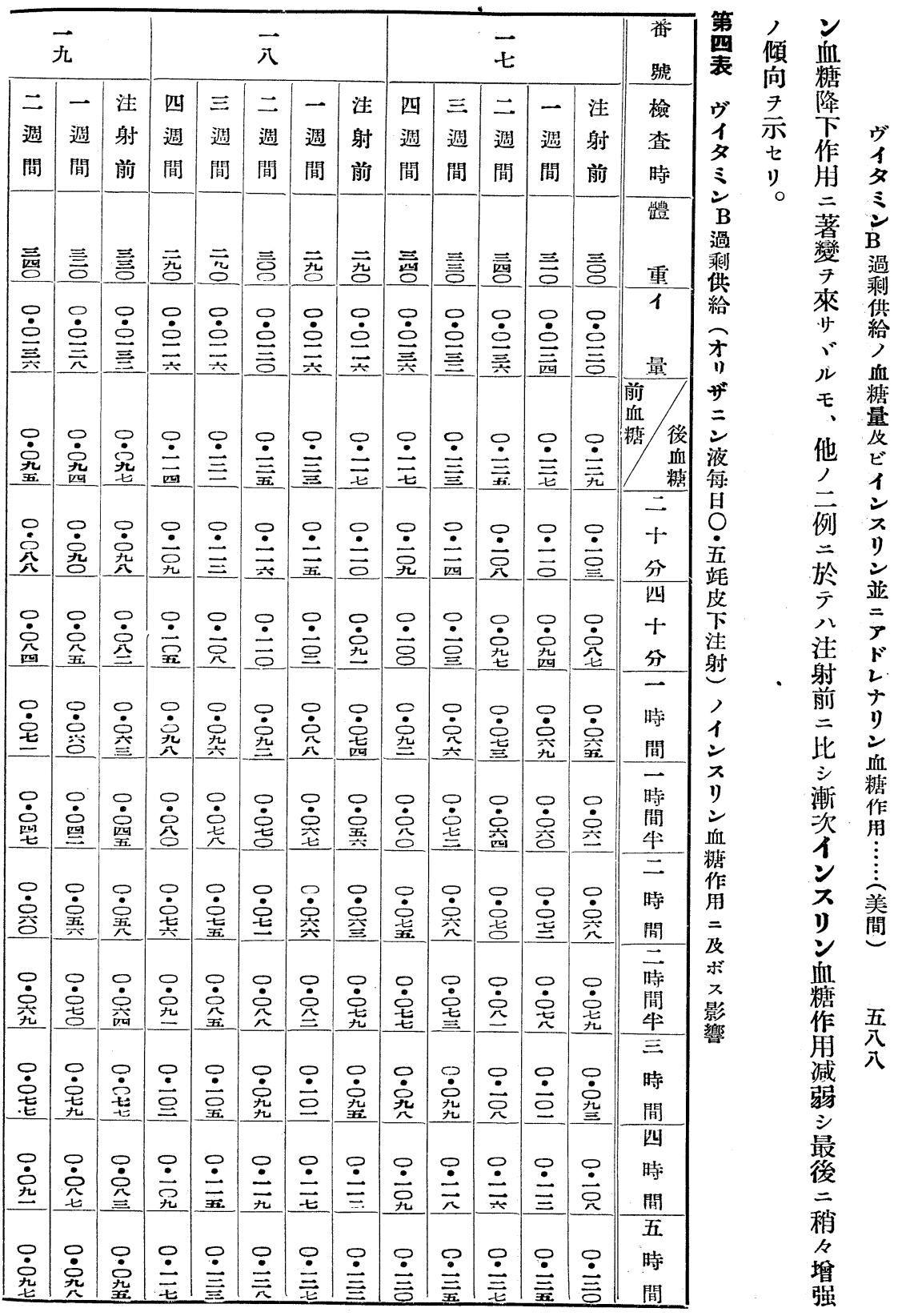


第三业第四表 第十八號白鼠二於々ル インスリン血糖曲線

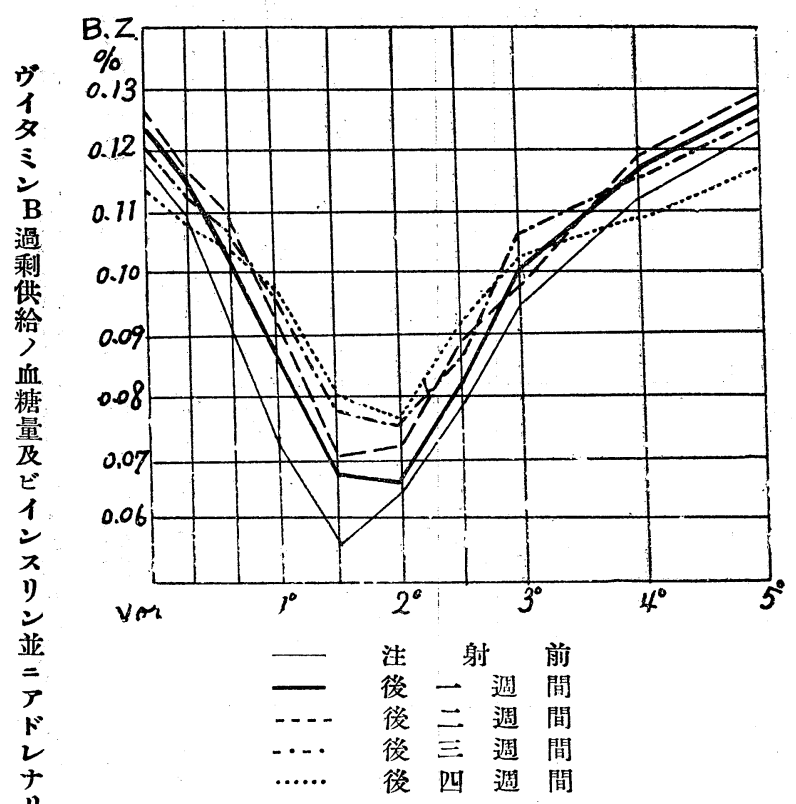

$\stackrel{2}{?}$

血

作学前宛 哥

$\vdots$ 體 㣻 至

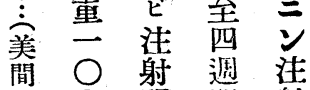

間 ○䀠 間 射

瓦開 間 射

五後 亘 7

五 付 司 早

○渵䦭續

○目注射

埕昆品二

竓早儿站

使倝泉或

角占会

當尗於立

\begin{tabular}{|c|c|c|c|c|}
\hline \multicolumn{4}{|c|}{$\overrightarrow{\overrightarrow{0}}$} & \\
\hline$\equiv$ & $=$ & $\rightarrow$ & 注 & $\equiv$ \\
\hline 週 & 週 & 遇 & 射 & 週 \\
\hline 間 & 間 & 間 & 前 & 間 \\
\hline 完 & 完 & 完 & 吾 & 営 \\
\hline $\begin{array}{l}\stackrel{0}{0} \\
\dot{0}\end{array}$ & $\stackrel{\dot{0}}{0}$ & $\dot{\dot{0}}$ & $\begin{array}{l}0 \\
\dot{0}\end{array}$ & $\dot{0}$ \\
\hline 空 & 三 & 亲 & 只 & 亚 \\
\hline$\stackrel{\circ}{0}$ & $\dot{0}$ & $\stackrel{9}{\dot{9}}$ & $\stackrel{0}{\dot{9}}$ & $\dot{0}$ \\
\hline 总 & 总 & 五 & 욜 & 卷 \\
\hline 号 & $\dot{\dot{\rho}}$ & $\dot{\dot{c}}$ & $\dot{\dot{R}}$ & $\dot{\dot{c}}$ \\
\hline & & 五 & & \\
\hline 号 & $\begin{array}{l}\stackrel{\rho}{\dot{0}} \\
\text { 全 }\end{array}$ & 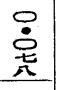 & $\begin{array}{l}0 \\
\dot{\dot{c}} \\
\text { 吾 } \\
\end{array}$ & 完 \\
\hline 足 & 웅 & $\begin{array}{l}8 \\
\stackrel{8}{S} \\
\end{array}$ & $\begin{array}{l}0 \\
\dot{0} \\
\text { 恶 } \\
\end{array}$ & $\begin{array}{l}\text { 웅 } \\
\text { 尊 }\end{array}$ \\
\hline 울 & 웅 & 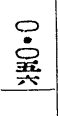 & $\begin{array}{l}0 \\
\dot{\rho} \\
\end{array}$ & $\begin{array}{l}\stackrel{\rho}{\circ} \\
\text { 吾 }\end{array}$ \\
\hline $\begin{array}{l}\stackrel{0}{\dot{0}} \\
\text { 茜 } \\
\end{array}$ & $\begin{array}{l}\stackrel{0}{0} \\
\dot{\rho} \\
\end{array}$ & $\begin{array}{l}\stackrel{0}{0} \\
\text { 突 } \\
\end{array}$ & $\begin{array}{l}0 \\
\text { 㞣 } \\
\end{array}$ & $\begin{array}{l}0 \\
\dot{0} \\
\text { 㫫 } \\
\end{array}$ \\
\hline $\begin{array}{l}\stackrel{0}{\dot{\alpha}} \\
\stackrel{\underline{\underline{E}}}{=}\end{array}$ & 虽 & $\begin{array}{l}0 \\
\text { 定 } \\
\end{array}$ & $\begin{array}{l}0 \\
\dot{0} \\
\text { 全 }\end{array}$ & $\begin{array}{l}\stackrel{0}{\dot{0}} \\
\stackrel{\underline{t}}{\equiv} \\
\end{array}$ \\
\hline $\begin{array}{l}\text { 兑 } \\
\text { 茜 }\end{array}$ & $\begin{array}{l}0 \\
\dot{c} \\
\text { 望 }\end{array}$ & $\begin{array}{l}\stackrel{\dot{\rho}}{2} \\
\text { 总 }\end{array}$ & $\begin{array}{l}0 \\
\dot{0} \\
\text { 兄 } \\
\end{array}$ & 号 \\
\hline$\stackrel{\circ}{\circ}$ & $\begin{array}{l}\stackrel{0}{0} \\
\text { 总 }\end{array}$ & $\stackrel{\circ}{\dot{0}}$ & $\begin{array}{l}0 \\
\dot{0} \\
\text { 染 } \\
\end{array}$ & 兑 \\
\hline$\therefore$ & $\stackrel{8}{\circ}$ & $\stackrel{\circ}{\circ}$ & $\stackrel{\circ}{\circ}$ & $\stackrel{1}{\circ}$ \\
\hline$\dot{8}$ & 总 & $\vec{c}$ & 豆 & 8 \\
\hline
\end{tabular}




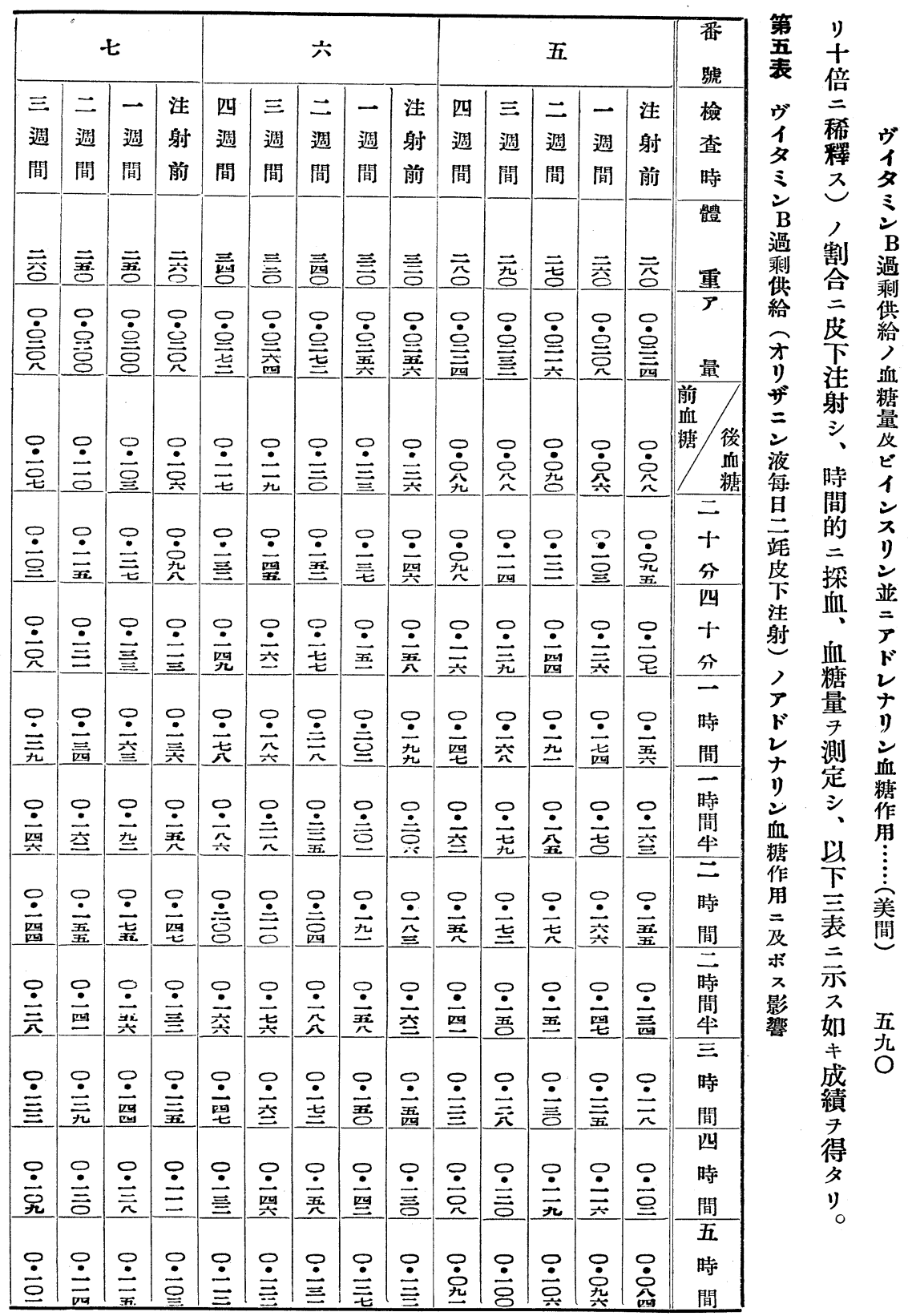




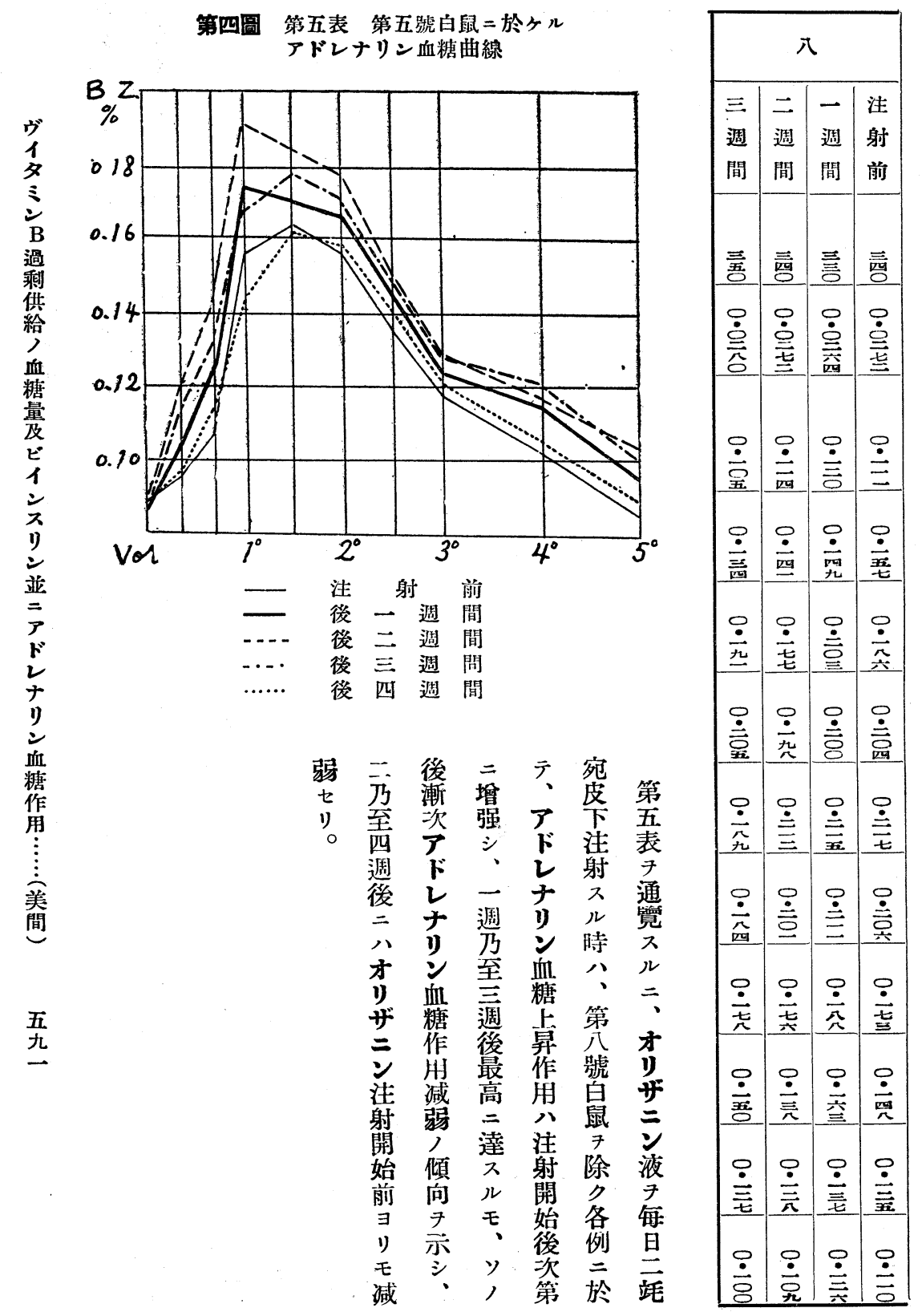




\begin{tabular}{|c|c|c|c|c|c|c|c|c|c|c|c|c|c|c|c|c|c|}
\hline & \multicolumn{4}{|c|}{ 五 } & \multicolumn{5}{|c|}{ 西 } & \multicolumn{5}{|c|}{ झ } & & & \\
\hline 注 & $\equiv$ & $=$ & $\rightarrow$ & 注 & 四 & $\equiv$ & $=$ & $\rightarrow$ & 注 & 四 & $\equiv$ & $=$ & $\rightarrow$ & 注 & & & ヴ \\
\hline 射 & 邀 & 週 & 週 & 射 & 週 & 週 & 週 & 週 & 射 & 週 & 週 & 週 & 週 & 射 & & & 1 \\
\hline 前 & 間 & 間 & 間 & 前 & 間 & 間 & 間 & 間 & 前 & 間 & 問 & 間 & 間 & 前 & & & $\hat{\Sigma}$ \\
\hline 害 & 㤎 & 言 & 흥 & 言 & 言 & 完 & 云 & $\bar{E}$ & $\overline{\bar{z}}$ & 言 & 酡 & 言 & 言 & 言 & $I$ & & 渦 \\
\hline $\begin{array}{l}\stackrel{8}{0} \\
\text { 至 }\end{array}$ & 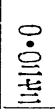 & $\begin{array}{l}\stackrel{8}{\circ} \\
\text { 空 }\end{array}$ & 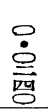 & 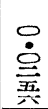 & 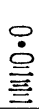 & 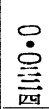 & 号 & 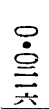 & 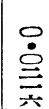 & $\begin{array}{l}\stackrel{\circ}{\dot{O}} \\
\text { 卆 }\end{array}$ & $\begin{array}{l}\stackrel{\circ}{\dot{g}} \\
\text { 苋 }\end{array}$ & $\stackrel{\stackrel{0}{0}}{\stackrel{+}{+}}$ & $\begin{array}{l}\stackrel{8}{\dot{S}} \\
\text { 究 }\end{array}$ & $\begin{array}{l}\stackrel{8}{0} \\
\stackrel{0}{n}\end{array}$ & & & 給 \\
\hline $\begin{array}{l}\stackrel{8}{\text { 总 }} \\
\end{array}$ & $\begin{array}{l}\text { 足 } \\
\text { 全 }\end{array}$ & 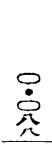 & $\stackrel{\text { : }}{\text { 总 }}$ & 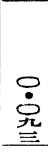 & 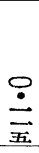 & $\stackrel{\circ}{\stackrel{\varrho}{\Xi}}$ & 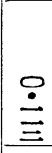 & 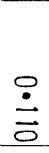 & 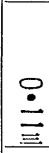 & $\stackrel{\circ}{\risingdotseq}$ & 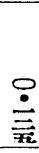 & $\stackrel{?}{\dot{\bar{\pi}}}$ & 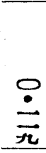 & $\stackrel{\circ}{\stackrel{\Xi}{\Xi}}$ & & & \\
\hline 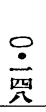 & 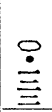 & 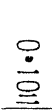 & 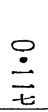 & 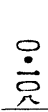 & $\frac{\stackrel{8}{0}}{\text { 要 }}$ & 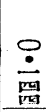 & $\stackrel{\ominus}{\stackrel{\equiv}{\equiv}}$ & $\stackrel{\rho}{\stackrel{\vec{\lambda}}{r}}$ & $\stackrel{\stackrel{\varrho}{\bar{E}}}{ }$ & 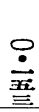 & 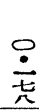 & 妾 & 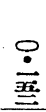 & $\stackrel{\circ}{\text { 全 }}$ & & & \\
\hline 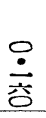 & 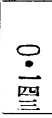 & 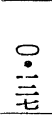 & 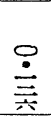 & 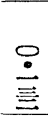 & 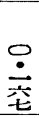 & $\stackrel{\text { 宅 }}{\text { 足 }}$ & 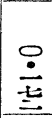 & 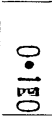 & 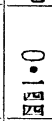 & 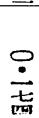 & 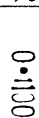 & 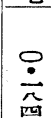 & 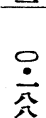 & $\stackrel{\circ}{\text { 䔰 }}$ & & & \\
\hline 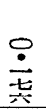 & 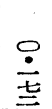 & $\stackrel{\circ}{\stackrel{\circ}{E}}$ & 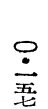 & $\stackrel{\text { 它 }}{\text { 艺 }}$ & 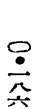 & $\stackrel{\varrho}{\stackrel{\Xi}{\Xi}}$ & 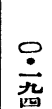 & 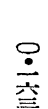 & $\stackrel{\circ}{\stackrel{\text { 无 }}{2}}$ & $\stackrel{\circ}{\dot{x}}$ & 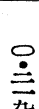 & 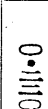 & $\stackrel{\text { 竞 }}{ }$ & $\stackrel{8}{\text { 究 }}$ & & & \\
\hline 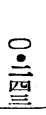 & 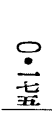 & $\stackrel{\circ}{\stackrel{\circ}{\underline{E}}}$ & $\stackrel{\stackrel{\rho}{\underline{\underline{\pi}}}}{\underline{\underline{n}}}$ & 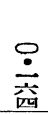 & 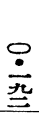 & 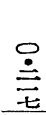 & $\stackrel{\text { 竞 }}{\text { 足 }}$ & 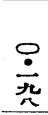 & 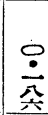 & 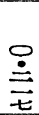 & 章 & 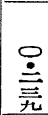 & 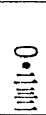 & $\stackrel{\text { 立 }}{ }$ & & & \\
\hline 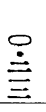 & $\stackrel{9}{\stackrel{\text { 公 }}{2}}$ & $\stackrel{\stackrel{\ominus}{\dot{x}}}{\text { 吾 }}$ & $\stackrel{8}{\dot{\underline{E}}}$ & $\stackrel{\circ}{\stackrel{\circ}{\circ}}$ & $\stackrel{\circ}{\overline{\bar{g}}}$ & $\frac{8}{\text { 突 }}$ & 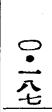 & $\stackrel{\stackrel{\ominus}{\grave{\hat{\lambda}}}}{\underline{\underline{E}}}$ & $\stackrel{\stackrel{\varphi}{\dot{z}}}{\text { 它 }}$ & $\stackrel{\circ}{\text { 究 }}$ & 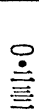 & 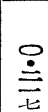 & 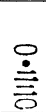 & $\stackrel{\circ}{\grave{\bar{O}}}$ & & & $\begin{array}{l}\text { 㤰 } \\
\text { 角 } \\
\text { 及 }\end{array}$ \\
\hline 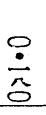 & 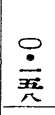 & 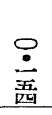 & 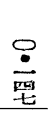 & 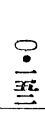 & 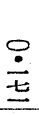 & 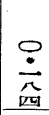 & 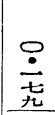 & $\stackrel{\circ}{\dot{\alpha}}$ & 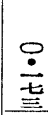 & 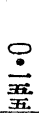 & 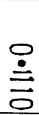 & 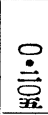 & 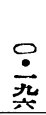 & $\stackrel{\stackrel{\varphi}{\dot{t}}}{\text { 荎 }}$ & & & \\
\hline 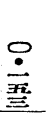 & 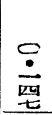 & 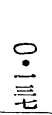 & 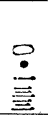 & 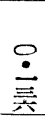 & $\stackrel{\ominus}{\dot{\underline{\Xi}}}$ & 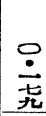 & 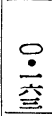 & 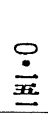 & 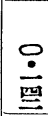 & 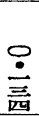 & $\stackrel{\text { 产 }}{\text { 兌 }}$ & 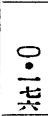 & 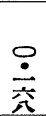 & $\stackrel{\circ}{\dot{\grave{玉}}}$ & & & \\
\hline 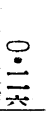 & 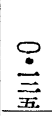 & $\stackrel{\circ}{\grave{0}}$ & $\stackrel{\circ}{\dot{\alpha}}$ & 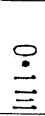 & 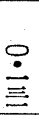 & $\stackrel{\circ}{\stackrel{\dot{x}}{\text { 至 }}}$ & 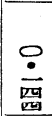 & 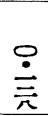 & 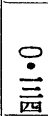 & $\stackrel{\varnothing}{\equiv}$ & $\stackrel{\circ}{\stackrel{\text { 突 }}{2}}$ & $\stackrel{?}{\dot{\overrightarrow{\vec{t}}}}$ & 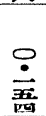 & 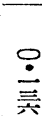 & 月 & & \\
\hline$\stackrel{\circ}{\dot{0}}$ & $\frac{0}{8}$ & 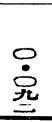 & 完 & $\stackrel{8}{\text { 旮 }}$ & $\stackrel{\circ}{\dot{亠}}$ & $\stackrel{\text { 竞 }}{ }$ & 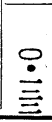 & 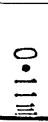 & 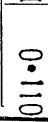 & $\stackrel{\varrho}{\underline{E}}$ & 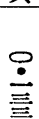 & 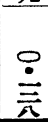 & $\stackrel{\stackrel{\varrho}{\equiv}}{ }$ & 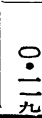 & 7 & & \\
\hline
\end{tabular}




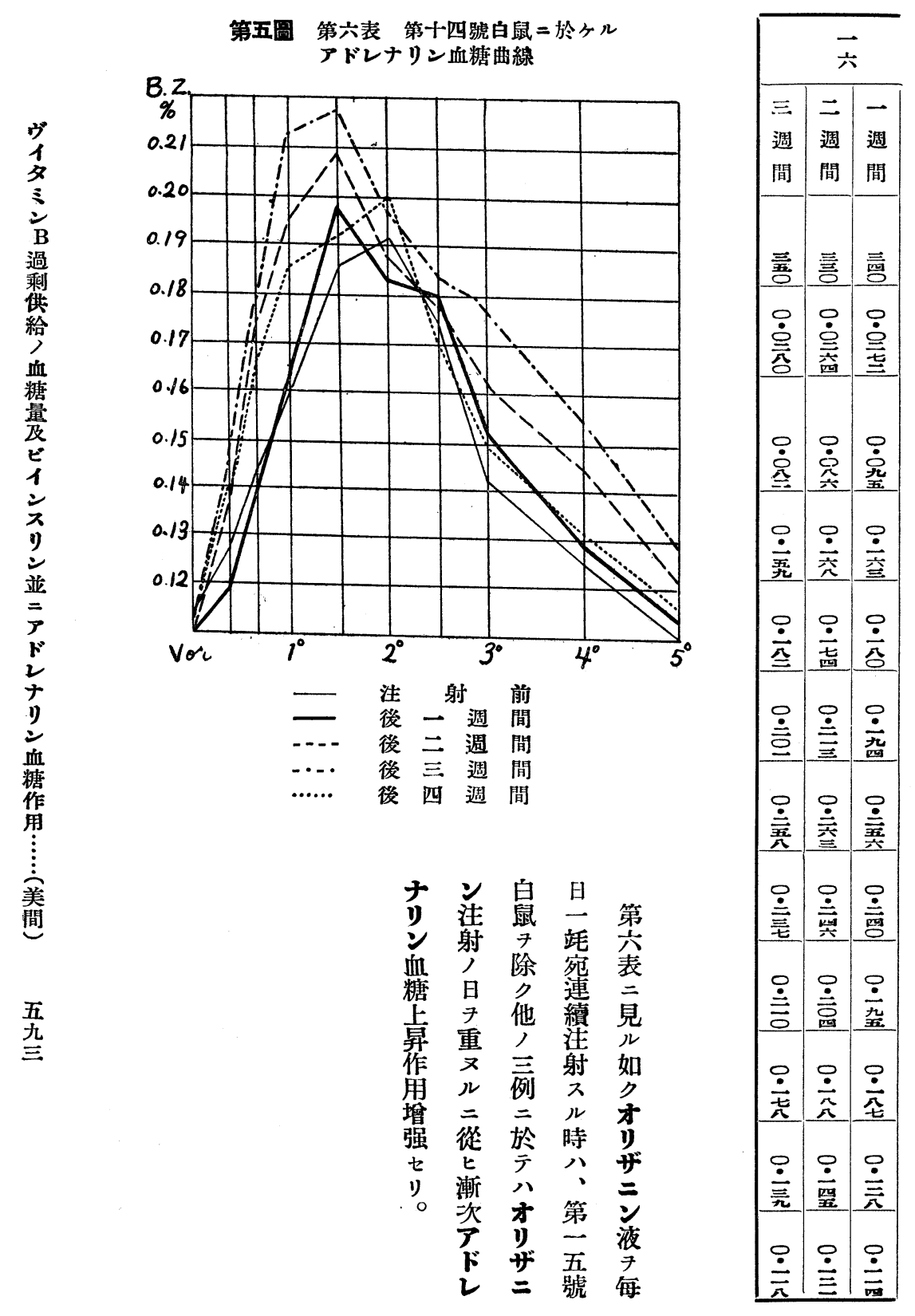




\begin{tabular}{|c|c|c|c|c|c|c|c|c|c|c|c|c|c|c|c|c|}
\hline & \multicolumn{4}{|c|}{ 卞 } & \multicolumn{5}{|c|}{ 三 } & \multicolumn{5}{|c|}{$\equiv$} & 番 & 槖 \\
\hline 注 & $\Xi$ & $=$ & - & 注 & 四 & $\equiv$ & 二 & - & 注 & 四 & $\equiv$ & $=$ & - & 注 & 檢 & ヴ \\
\hline 射 & 週 & 週 & 週 & 射 & 週 & 週 & 䓢 & 週 & 射 & 週 & 週 & 週 & 週 & 射 & 查 & $\begin{array}{l}1 \\
\text { 夕 }\end{array}$ \\
\hline 前 & 間 & 間 & 間 & 前 & 間 & 間 & 間 & 間 & 前 & 間 & 閒 & 問 & 間 & 前 & 時 & $\Sigma$ \\
\hline$\overline{\bar{t}}$ & 吾 & 言 & 言 & 三 & 壳 & 彭 & 带 & 票 & 帚 & 三 & 言 & $\overline{\overline{8}}$ & $\overline{\tilde{\sigma}}$ & $\overline{\bar{\pi}}$ & $\begin{array}{l}\text { 體 } \\
\text { 重 } \\
\end{array}$ & $\begin{array}{l}\text { B } \\
\text { 過 } \\
\text { 剩 } \\
\text { 供 }\end{array}$ \\
\hline 吊 & 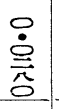 & 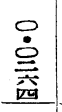 & 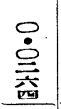 & 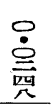 & 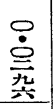 & $\begin{array}{l}\stackrel{0}{0} \\
\text { 究 } \\
\end{array}$ & $\begin{array}{l}0 \\
\dot{O} \\
\\
\end{array}$ & 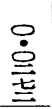 & $\begin{array}{l}\stackrel{\circ}{0} \\
\text { 응 }\end{array}$ & 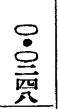 & 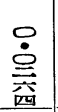 & 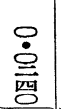 & 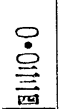 & 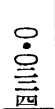 & $\Gamma$ & 給 \\
\hline$\stackrel{\stackrel{\varphi}{0}}{0}$ & $\stackrel{\circ}{\dot{\dot{\alpha}}}$ & $\stackrel{\circ}{\dot{亠}}$ & $\dot{\dot{0}}$ & 兑 & $\begin{array}{l}0 \\
\stackrel{0}{0} \\
\text { 五 }\end{array}$ & 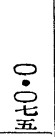 & 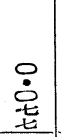 & $\begin{array}{l}\text { 足 } \\
\text { 定 }\end{array}$ & 웅 & $\stackrel{\circ}{\doteq}$ & 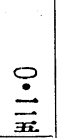 & 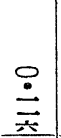 & 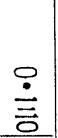 & 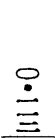 & 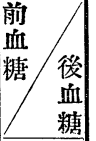 & $\begin{array}{l}\stackrel{サ ゙}{二} \\
\stackrel{ \pm}{*} \\
\text { 液 } \\
\text { 每 }\end{array}$ \\
\hline$\stackrel{\circ}{\dot{\Sigma}}$ & 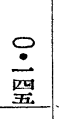 & $\stackrel{\text { 号 }}{\text { 尊 }}$ & $\stackrel{\circ}{\dot{\Xi}}$ & $\stackrel{\circ}{\stackrel{一}{\overline{\bar{z}}}}$ & 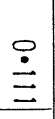 & $\stackrel{\circ}{\text { 亲 }}$ & 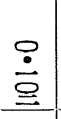 & 足 & $\begin{array}{l}\text { 完 } \\
\text { 学 }\end{array}$ & 兰 & $\stackrel{\stackrel{\ominus}{\dot{\nabla}}}{\text { 苜 }}$ & $\stackrel{\text { 至 }}{\text { 至 }}$ & 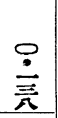 & 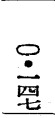 & $\begin{array}{l}\bar{二} \\
+ \\
\text { 分 }\end{array}$ & $\begin{array}{l}\text { 昌 } \\
\text { 家 } \\
\text { 站 }\end{array}$ \\
\hline$\stackrel{\text { 吾 }}{\text { 吾 }}$ & $\stackrel{\circ}{\dot{\Xi}}$ & 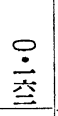 & 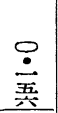 & 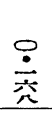 & $\stackrel{\text { 竞 }}{\text { 票 }}$ & 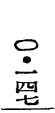 & 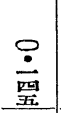 & $\stackrel{\circ}{\stackrel{\Xi}{\doteq}}$ & 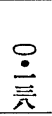 & $\stackrel{\circ}{\stackrel{\circ}{\dot{\pi}}}$ & $\stackrel{\circ}{\dot{\AA}}$ & $\stackrel{\circ}{\stackrel{\check{\pi}}{\text { 亲 }}}$ & 产 & 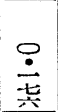 & $\begin{array}{l}\text { 四 } \\
+ \\
\text { 分 }\end{array}$ & 落 \\
\hline 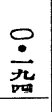 & 兰 & 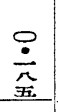 & 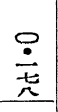 & 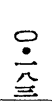 & 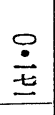 & 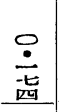 & 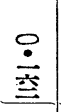 & $\stackrel{\stackrel{\circ}{\dot{m}}}{\text { 吾 }}$ & $\stackrel{\text { 富 }}{\text { 罡 }}$ & 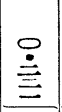 & 号 & $\stackrel{\circ}{\stackrel{亠}{a}}$ & $\begin{array}{l}\stackrel{\dot{\Xi}}{\text { 吾 }} \\
\end{array}$ & 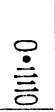 & $\begin{array}{l}\overrightarrow{\text { 時 }} \\
\text { 間 }\end{array}$ & $\begin{array}{l}3 \\
3 \\
5\end{array}$ \\
\hline 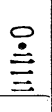 & 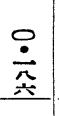 & $\stackrel{\stackrel{\rho}{\underline{\lambda}}}{\underline{\underline{n}}}$ & $\stackrel{\circ}{\stackrel{\AA}{0}}$ & $\stackrel{\text { 室 }}{\text { 苪 }}$ & 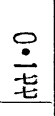 & $\stackrel{9}{\dot{\lambda}}$ & $\stackrel{8}{\dot{\dot{t}}}$ & $\frac{\stackrel{\circ}{\dot{E}}}{\text { E }}$ & $\stackrel{\circ}{\stackrel{\text { 妾 }}{2}}$ & 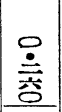 & 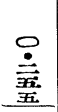 & $\stackrel{\text { 完 }}{\text { 空 }}$ & 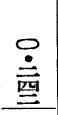 & 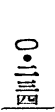 & $\begin{array}{l}\text { 荟 } \\
\text { 間 } \\
\text { 牛 }\end{array}$ & $\begin{array}{l}+ \\
\vdots \\
\vdots \\
\end{array}$ \\
\hline$\stackrel{\circ}{\dot{\dot{x}}}$ & $\stackrel{\circ}{\text { 究 }}$ & $\stackrel{\text { 宅 }}{\underline{E}}$ & $\stackrel{\circ}{\stackrel{\text { 亮 }}{2}}$ & $\stackrel{\circ}{\text { 夏 }}$ & 兰 & $\stackrel{\text { 究 }}{\text { 究 }}$ & 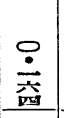 & 咅 & 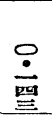 & 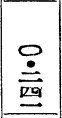 & $\stackrel{\text { 竞 }}{ }$ & 兰 & 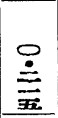 & 旁 & $\begin{array}{l}\text { 二 } \\
\text { 時 } \\
\text { 間 }\end{array}$ & $\begin{array}{l}\text { 血糖 } \\
\text { 仵 }\end{array}$ \\
\hline 首 & 号 & 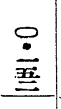 & 兰 & 只 & 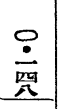 & 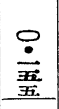 & 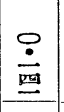 & 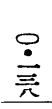 & 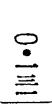 & 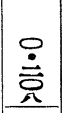 & $\begin{array}{l}\stackrel{0}{\dot{\Xi}} \\
\text { 으 }\end{array}$ & $\stackrel{8}{\dot{\grave{\lambda}}}$ & 息 & 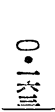 & $\begin{array}{l}\text { 時 } \\
\text { 間 } \\
\text { 牛 }\end{array}$ & $\begin{array}{l}\text { 这 } \\
\text { ボ } \\
\text { 影 }\end{array}$ \\
\hline 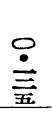 & $\stackrel{\circ}{\grave{⿱ 亠 幺}}$ & 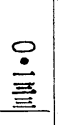 & 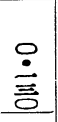 & 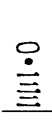 & $\stackrel{\circ}{\stackrel{\bar{\Xi}}{\underline{\pi}}}$ & 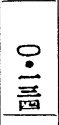 & 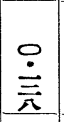 & 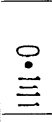 & 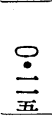 & 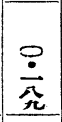 & 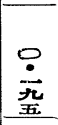 & $\stackrel{\circ}{\stackrel{\circ}{\dot{5}}}$ & 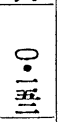 & 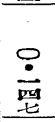 & $\begin{array}{l}\Xi \\
\text { 時 } \\
\text { 間! }\end{array}$ & \\
\hline$\stackrel{\circ}{\dot{\dot{O}}}$ & 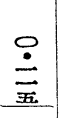 & $\stackrel{\circ}{\risingdotseq}$ & $\stackrel{\circ}{\stackrel{\Xi}{E}}$ & $\stackrel{\stackrel{\rho}{\dot{\theta}}}{ }$ & $\stackrel{\circ}{\dot{\dot{D}}}$ & $\stackrel{\stackrel{\rho}{\dot{\vec{E}}}}{ }$ & $\stackrel{\circ}{\dot{0}}$ & $\begin{array}{l}\stackrel{0}{\dot{d}} \\
\text { 奠 }\end{array}$ & $\stackrel{?}{\dot{0}}$ & $\begin{array}{l}\text { 兰 } \\
\text { 咅 }\end{array}$ & $\stackrel{\circ}{\stackrel{\circ}{\text { 全 }}}$ & $\stackrel{\stackrel{\circ}{\dot{m}}}{\underline{\underline{\underline{m}}}}$ & $\stackrel{\circ}{\stackrel{\text { 妾 }}{2}}$ & 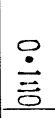 & $\begin{array}{l}\text { 四 } \\
\text { 時 } \\
\text { 間 }\end{array}$ & \\
\hline$\stackrel{\circ}{\circ}$ & $\frac{0}{\dot{D}}$ & $\stackrel{\circ}{\doteq}$ & 움 & $\stackrel{\dot{\dot{O}}}{\varrho}$ & $\dot{8}$ & \begin{tabular}{|l}
0 \\
忘苪 \\
\end{tabular} & $\left|\begin{array}{l}0 \\
\dot{c}\end{array}\right|$ & $\begin{array}{l}0 \\
\dot{\alpha} \\
\text { 人 }\end{array}$ & 忠 & $\frac{9}{\dot{\bar{\Delta}}}$ & $\stackrel{9}{\dot{\bar{\Xi}}}$ & 兰 & 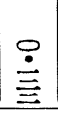 & 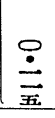 & $\begin{array}{l}\text { 五 } \\
\text { 時 } \\
\text { 間 }\end{array}$ & \\
\hline
\end{tabular}




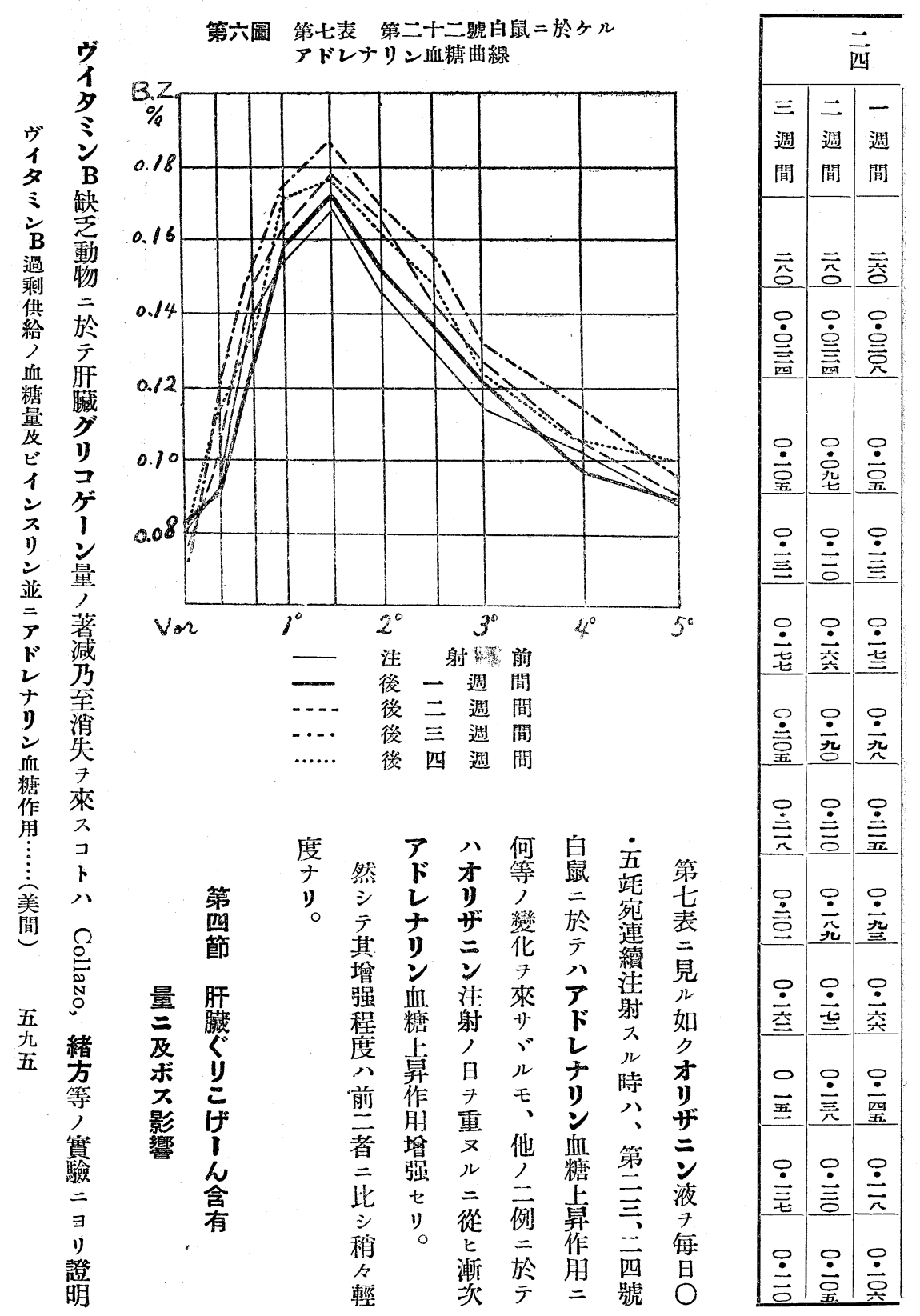


第九表 オリザニン液二䇇宛皮下注射

\begin{tabular}{|c|c|c|c|}
\hline 日十 & 日二十二 & 日十 & 星注 \\
\hline 平三豆 & 平 均七四三 & 平六五二一 & $\begin{array}{l}\text { 番 } \\
\text { 號 }\end{array}$ \\
\hline $\begin{array}{l}\text { 面亲 } \\
0\end{array}$ & $\begin{array}{l}\text { 吾亲酉三 } \\
0\end{array}$ & 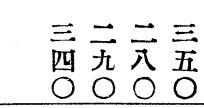 & $\begin{array}{l}\text { 體 } \\
\text { 重 }\end{array}$ \\
\hline $\begin{array}{l}\text { 七六 } \\
\text { 五酉 }\end{array}$ & $\begin{array}{l}\text { 八五六士 } \\
\text { 六四主 }\end{array}$ & 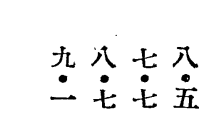 & $\begin{array}{l}\text { 肝 } \\
\text { 藏 } \\
\text { 重 } \\
\text { 量 }\end{array}$ \\
\hline $\begin{array}{l}\text { ○只 } \\
\text { 吾立吾 } \\
\text { 声立至 }\end{array}$ & 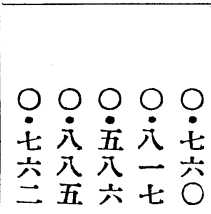 & 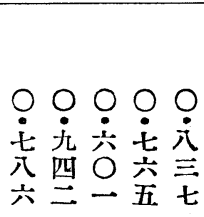 & 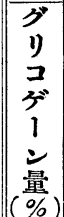 \\
\hline
\end{tabular}

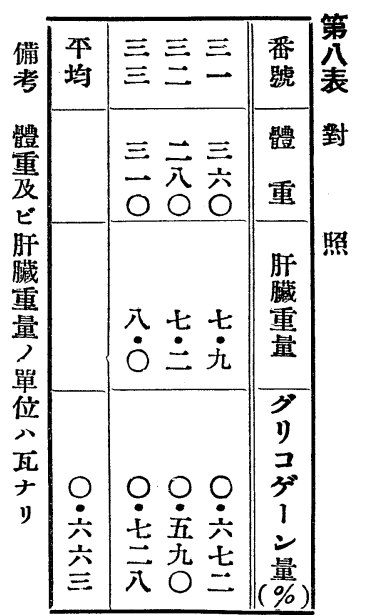

政

第十表 オリザニン液一竨宛皮下注射

\begin{tabular}{|c|c|c|c|}
\hline 日十 & 日二十二 & 日 $十$ 三 & 但注 \\
\hline 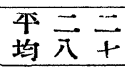 & 平均六五三二 & 平均四三 $\vec{O}$ 九 & 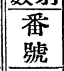 \\
\hline 吾三 & $\begin{array}{l}\text { 吾至至 } \\
0 \\
0\end{array}$ & $\begin{array}{c}\text { 无酉严咅 } \\
0\end{array}$ & $\begin{array}{l}\text { 體 } \\
\text { 重 }\end{array}$ \\
\hline 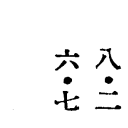 & $\begin{array}{l}\overrightarrow{0} \overrightarrow{0} \text { 七 } \\
\dot{-} \dot{1} \dot{0}\end{array}$ & 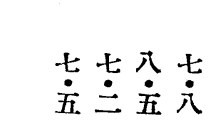 & $\begin{array}{l}\text { 䚽 } \\
\text { 藏 } \\
\text { 重 } \\
\text { 量 }\end{array}$ \\
\hline $\begin{array}{l}\text { ○ᄋ } \\
\text { 公忘童 } \\
\text { 吾突 }\end{array}$ & 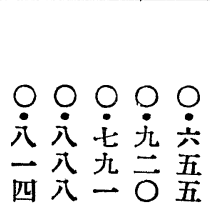 & 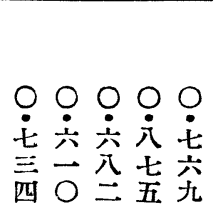 & 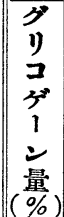 \\
\hline
\end{tabular}
当午占余量 导章 日ナ八二

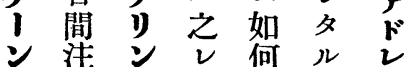
量射血子年所子 $\ni$ 糖 知ルナ 测タ作 今影リ 定儿用さ響。 白檢卜子然 第鼠查䍇然 分言テボバ 表就用上ス卢 至声 第监多節名 十須艎血要 表 示 ス

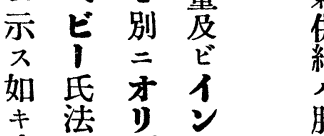
成 績 得 i) 


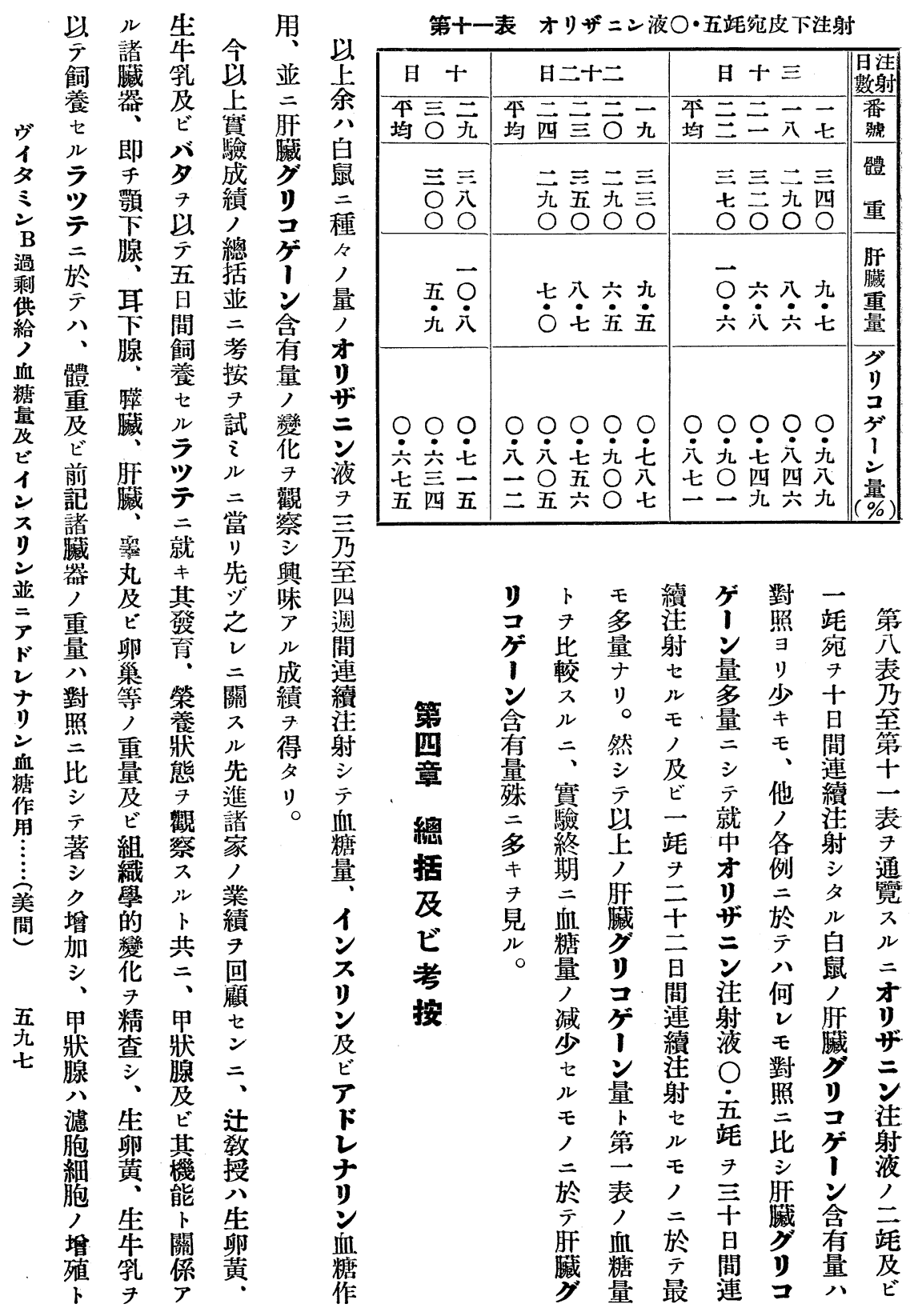




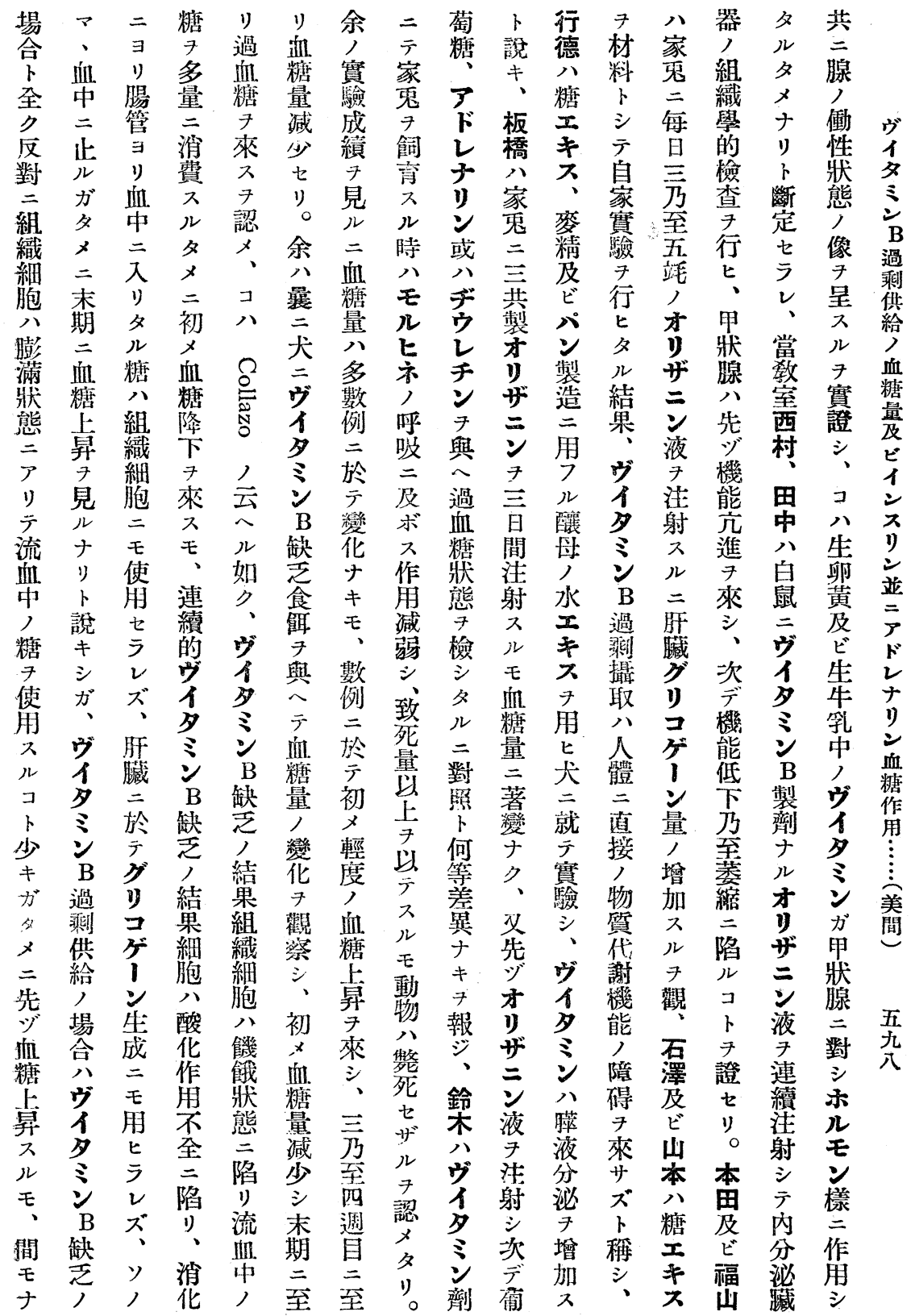




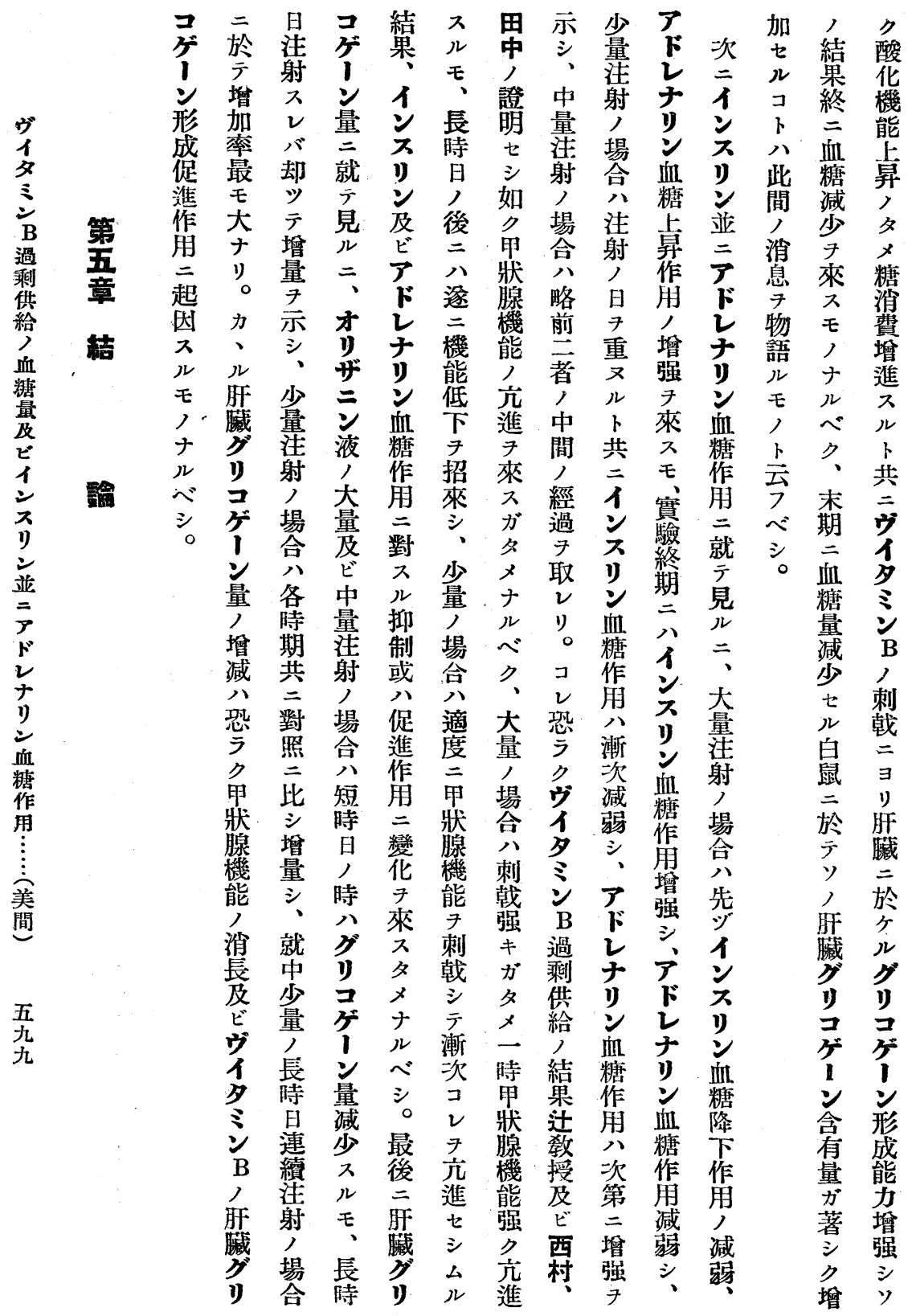




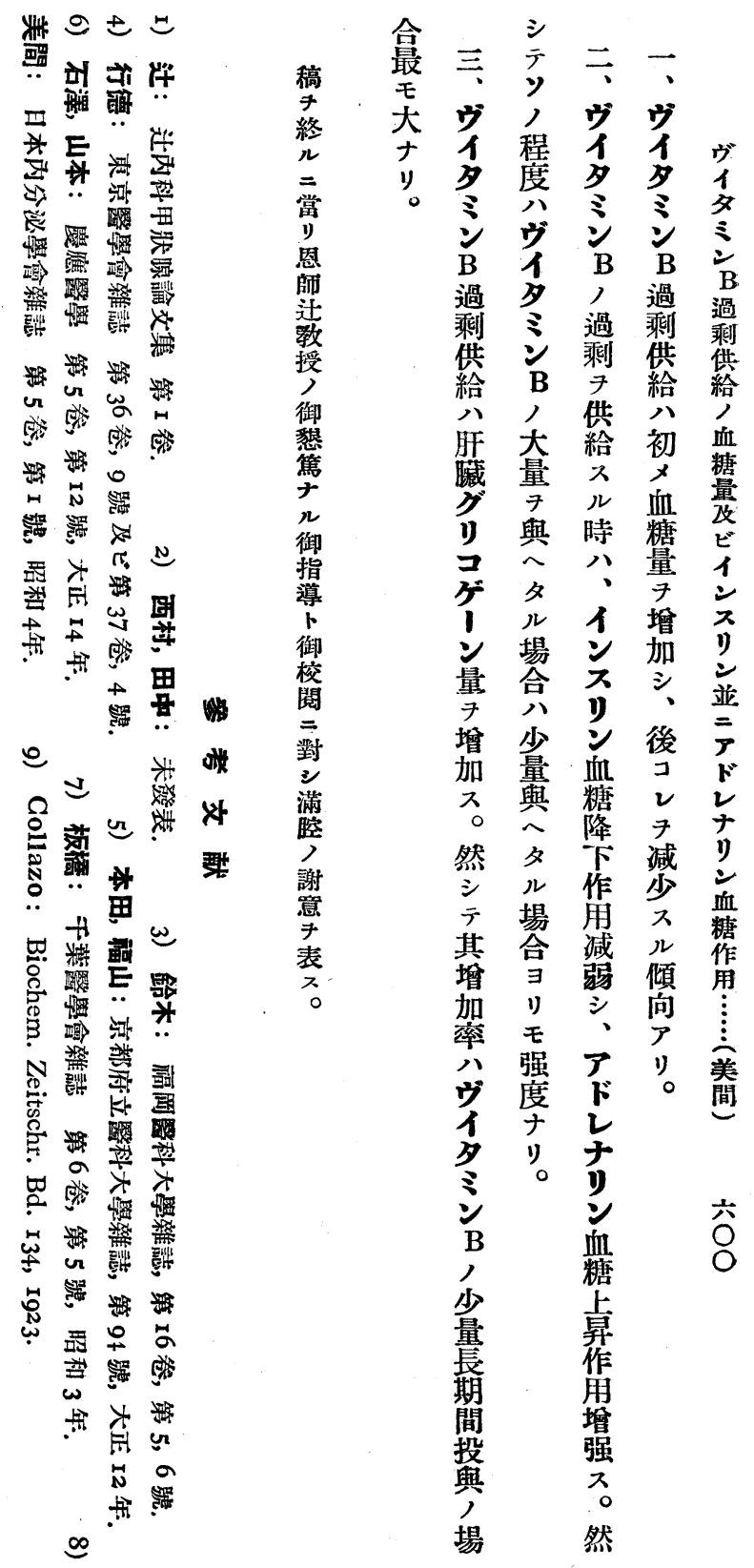


und steigern die Zuckertoleranż.

2) Diese Wirkung hält noch lange Zeit nach der letzten Zuckerinjektion an.

3) Diese Zuckerwirkung zeigt zeitliche Veränderung: Im Anfangsstadium wirkt die wiederholte Zuckerinjektion der Insulinwirkung entgegen und verstärkt die Adrenalinwirkung.

4) Wiederholte Kochsalzlösunginjektion (40 Tage lang) hat keinen bestimmten Einfluss auf die Insulin- u. Adrenalinblutzuckerwirkung und Zuckertoleranz.

5) Die histologische Untersuchung der endokrinen Drüsen der so behandelten Tiere lässt keine besondere Veränderung erkennen.

(Autoreferat.)

\section{UEBER DEN EINFLUSS VON UEBERSCHUESSIGEM \\ VITAMIN-B AUF DEN ZUCKERSTOFFWECHSEL BEI RATTEN.}

Von

Dr. T. Mima.

(Aus der I. med. Klinik der Kaiserl. Univers. zu Kyoto in Japan.

Direktor : Prof. Dr. K. Tsuji.)

- Der Verfasser injizierte mit normaler Kost gefütterten Ratten die Oryzaninlösung, ein Vitamin-B-praeparat, (täglich 2.0 , 1.0 und $0.5 \mathrm{ccm}$ pro Kopf) 3-4 Wochen lang und beobachtete die Veränderungen des Blutzuckerwertes, der Insulin- und Adrenalinblutzuckerwirkungen und des Glykogengehaltes der Leber.

Die Resultate sind die folgenden:

I) Bei der Darreichung von Vitamin-B im Ueberschusse verändert sich der Blutzucker bei manchen Ratten nicht, bei einigen jedoch vermehrt er sich im Frühstadium und vermindert sich im Spätstadium. 
2) Der Ueberschuss vom Vitamin-B schwächt die Insulinhypoglykämie und verstärkt die Adrenalinhyperglykämie. Diese Wirkungen sind stärker bei der Darreichung einer grossen Menge vom Vitamin-B als einer kleinen.

3) Der Ueberschuss vom Vitamin-B vermehrt den Glykogengehalt der Leber. Diese Wirkung ist am stärksten, wenn man kleine Mengen lange Zeit hindurch injiziert.

(Autoreferat)

\section{UEBER DEN EINFLUSS DER INNERSEKRETORISCHEN \\ DRÜSEN AUF DEN NATRIUMCHLORID- UND \\ CALCIUMSTOFFWECHSEL BEI HUNDEN \\ IM HUNGERZUSTANDE \\ Von}

Dr. M. Mizokami und Dr. S. Nishimura.

(Aus der I. med. Klinik der Kaiserl. Universität zu Kyoto.

Direktor: Prof. Dr. K. Tsuji.)

Um die Beziehung zwischen der inneren Sekretion und dem $\mathrm{NaCl}$ - oder Ca-stoffwechsel im Hungerzustande festzustellen, führten die Verfasser zuerst zur Kontrolle die estimmung des $\mathrm{NaCl}$ oder $\mathrm{Ca}$ im Harne an Hunden bei normaler Fütterung und im Hungerzustande aus und studierten dann an denselben Tieren die Einwirkung der Schilddrüsensubstanzfütterung, der Schilddrüsenexstirpation und wiederholter Adrenalin- oder Insulininjektion auf dieselben während der Fütterungs- und Hungerperiode.

Die Resultate sind die folgenden:

A. Ueber die NaCl-ausscheidung.

I) Bei den gesunden Hunden nimmt die $\mathrm{NaCl}$-ausscheidung im Harne während des Hungerns im allgemeinen $a b$, d. h. bis zum 3. oder 4. Tage rasch, danach allmählich. 